\title{
Potential Study of Water Extraction from Selected Plants
}

\author{
$S$. Musa ${ }^{1, *}, N . A . A$. Abu Mansor ${ }^{1}, S . S$. Bujang ${ }^{1}, N . A . F$. Mohd Kamil ${ }^{1}, M . S$. Adnan ${ }^{1}$ and $R$. \\ Hamdan $^{2}$ \\ ${ }^{1}$ Faculty of Civil and Environmental Engineering, Universiti Tun Hussein Onn Malaysia,86400, Batu \\ Pahat, Johor, Malaysia \\ ${ }^{2}$ Faculty of Engineering Technology, Universiti Tun Hussein Onn Malaysia,86400, Batu Pahat, Johor, \\ Malaysia
}

\begin{abstract}
Water is absorbed by the roots of a plant and transported subsequently as a liquid to all parts of the plant before being released into the atmosphere as transpiration. In this study, seven(7)selected plant species collected from urban, rural and forested areas were studied and characterized. The water was collected using transparent plastic bag that being tied to the tree branches. Then, the vapouris water trapped inside the plastic bag and through the condensation process, it become water droplets. Water quality parameters such as temperature, $\mathrm{pH}$ value, DO, turbidity, colour, magnesium, calcium, nitrate and chloride were analyzed. The analysis was compared to drinking water quality standard set by the Ministry of Health Malaysia. Based on the results, it shows that banana leaf has a higher rate of water extraction compared to others. Thus, the plant can be categorised as a helpful guide for emergency use of water or as an alternative source to survival.
\end{abstract}

\section{Introduction}

Generally, the inclusion of water in the human body is determined by stimulation of thirst. When the volume of water lost from the body is higher than the volume of water consumed, the osmotic pressure of the extra cellular fluid (ECF) will increase. Anti diuretic hormone $(\mathrm{ADH})$ is released from the hypothalamus gland osmoreceptors pituitary when activated[1]. The increase in both the osmotic pressure of the extracellular fluid and antidiuretic hormone generate the urge of thirst in humans [2]. Lack of water intake into the human body can cause diseases such as dehydration and hyperthermia. The disease can lead to death if not treated immediately [3].

There are many sources of water on earth that can be used as a source of clean drinking water such as rivers, lakes and rainwater [4]. However, these resources are not always available in all circumstances, for example, in the area of human settlements far from clean water sources or in situations where travellers in the woods are lack of clean water to drink[5]. In a desperate situation, alternative water source should be considered so that

*Corresponding author: sabariah@uthm.edu.my 
people can still survive and to avoid health problems caused by lack of water in the body. One method that can be used is extracting water from plants.

Chand and Chang [6] stated that, the body of an adult human contains $60 \%$ of water, whilea new born baby is composed of more water (75\%) than that of elderly person $(50 \%)$. Also, the more muscular a body more water is contained. All our vital organs contain different amount of water, namely the brain, the lungs, the heart, the liver and the kidneys contain a large quantity of water between $65 \%-85 \%$ depending on the organ while bones contain less water (but still 31\%) [3].

There are several areas in Malaysia that still suffer the deficiency of clean water supply such as Ranau, Sabah [4]. This problem has led to some of the residents in the area to use water of unknown level of cleanliness as drinking water [7]. The same problem exists in forests. Travelling over long distance of forest tracks may have difficulty to get clean water to survive during the journey.

One of the survival method is collecting water from plants by means of its transpiration process. However, there is no study to indicate whether such a water is drinkable [5, 9]. This study is meant to compare the characteristics of the water collected from the transpiration process of plants with drinking water quality standards set by the Ministry of Health Malaysia[8].

\section{Extracting Transpiration of Plants}

Transpiration bags are often used in the laboratory to coax plant transpiration. It can also be used for survival as emergency supplies to collect water through the transpiration process. This method starts with incorporating as many leaf of a plant into the bag and then ties it tightly to its branch tip. Water vapour is expected to evaporate through the plant leaf surface and condensewithin the boundary of the plastic bag before falling into the edges as drops of water. Bags should be transparent so that the light can penetrate into the bagtoincreasethe rate of plant transpiration [7]. Some of the forest nomadic tribes are known to use the same method to collect water from plants. However, how safe the water for drinking by humans remains unknown.

\subsection{Soil Inspection and Location}

Soil inspection or geotechnical inspection is crucial in understanding the physical properties of soil and the rocks beneath the ground. Type of soils, soil moisture and groundwater content were analyzed to determine their properties as well as the characateristics. The water that derived from plant were compared with groundwater to determine the relationship between these two water to understand the effect of type soil and groundwater on the extraced water. Various tests are done to explore the sub-surface and surface characteristics of soil to estimate the plant-available concentrations of plant nutrients [3].

In this study, three (3) areas were chosen to identify the effects of water quality at difference locations and conditions, that covers urban area (Universiti Putra Malaysia, 43100 Serdanga, Selangor), rural area(Kg Serom 6, Sungai Mati, 84400 Muar, Johor) and forest area (Hutan Rekreasi Ayer Keroh Melaka, Lebuhraya Ayer Keroh, 75450 Melaka)(Fig. 1). These areas were selected because these area are known as a residential area that possible could apply this method to extract the water for their usage. The soil and water conditions are also analysed[10]. This is to identify any adverse effect in thewater extracted from the plants that may be due to the surrounding soils. Soil type and moisture content are recorded for each station [11]. 

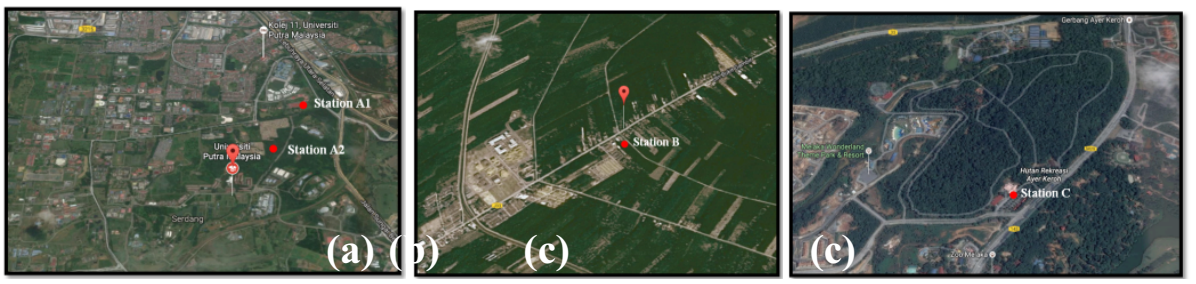

Fig. 1. (a) Urban area-UPM (b) rural area - Kg Serom 6 (c) forest area- Melaka

\subsection{Type of Plants}

The selection of plant at different locations is based on physical characteristics such as height and quantity of leaves. All selected plants should have thick bushes of leaves. This feature is emphasized in order to facilitate the work of water sampling to be carried out in which dense and shady leaves allow a plastic bag to be tied to a tree branch quickly and easily.

There are fruits plants, shrubs, flowers and poisonoustrees. These plants are selected because the plants grow well in the 3 areas [12]. These plants are also selected for its popularity and easily available in the vicinity of homes throughout Malaysia. This study will analyze the characteristics of the water parameters to be collected from the seven types. There are rambutan (Nephelium lappaceum), banana (Musa Paradisiaca), principal soursop (Annona muricata L.), flowers bells (Allamanda cathartica), shrimp clip (Heliconias), drasina (Dracaena fragrans), and flowerbeds setup (Bauhinia Kockiana).

\subsection{Water Sampling}

The use of transparent plastic bag for the purpose of water sampling has been justified at the beginning of Section 2. The size of the plastic bag is $25.4 \mathrm{~cm}$ x $40.64 \mathrm{~cm}$ for plants with small-size foliage such as rambutan, flowers bell, soursop, flowerbeds setup, drasina and heliconia. While plants with large-size foliage such as banana, the size of the plastic bag used is $50.8 \mathrm{~cm} \times 91.44 \mathrm{~cm}$ (Fig.2).

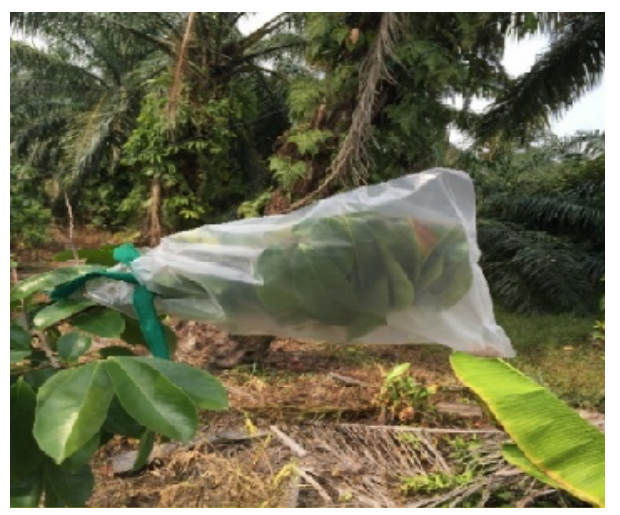

Fig. 2. Water sampling method 
Due to the larger size surface is uneven, the methods used to measure the surface area of rambutan, flowers bell, soursoup and flowering plants are setup using the graphical method. Through this method, the shape of the leaf surface will be drawn on graph paper, then the total area will be determined by calculating the total area of each plot in the graph. Fig. 3 shows how to calculate the surface area of leaf using the graphical method.

However, this method cannot be applied to such a large leaf such as banana leaf, drasina and heliconia. The large leaf surface area will measure using a measuring tape. The length and width of the leaf was analysed by usingtrapizodial estimation. Fig. 3 shows the method of measuring the length and width of leaves using a measuring tape. Numerous methods have been employed from time to time for the determination of leaf areas, but it was found impracticable to use any of these methods without modification [13].

Moreover, in terms of number of leaf that are involved, it can be seen that the trees have small leaf like flowers bell requires more number of leaf that need to be loaded into the plastic in order to produce water transpiration than trees that have a size large leaf such as banana leaf that only requires a single leaf transpiration of water to produce a sufficient sample for the purposes of this study. The time required to collect water samples for this sampling isone-day collection.

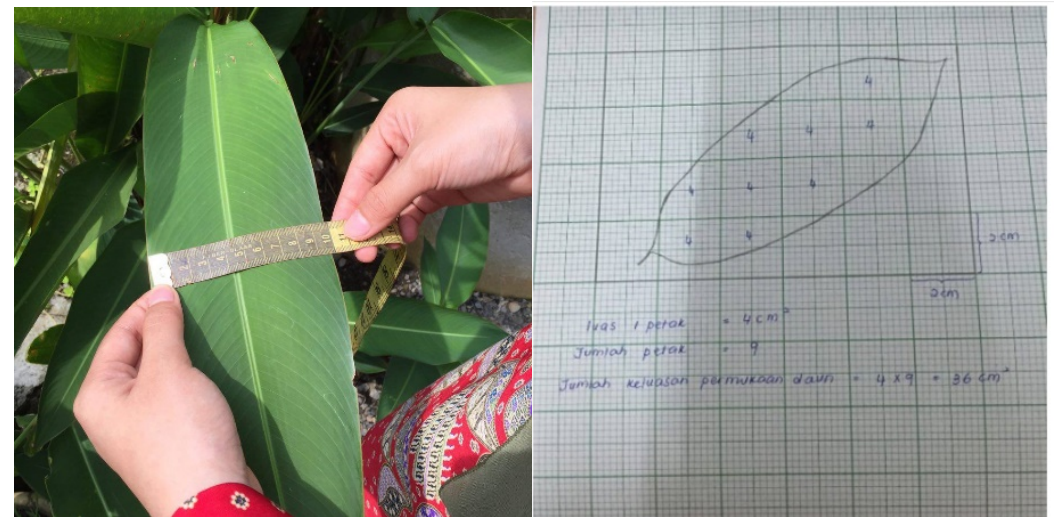

Fig. 3. Measurement of leaf surface area

With 60 minutes recording intervals, record the transpiration difference, average solar radiation and average saturated vapor pressure to analyze the model and formulate. The measuring intervals are the fitted measurement time for transpiration model of fitted plants.

The quantity of water should also be taken into account in terms of dependence on the light, the surface area of leaf and number of leaf [13]. Stomatal dimensions were determined with an ocular micrometer with the leaves attached to the plant $[11,14]$.High of temperature and the larger surface area of leaf or leaf number, will increase the total volume of water collected. Beside, if the weather is cloudy and less sunlight, volume of water also decrease in time. Transpiration process plant will be higher in the presence of abundant sunshine compared with less sunlight conditions [15].

\subsection{Water Quality Assessment}

Water quality is the whole process of evaluation of physical, chemical and biological water properties relating to the quality of natural, human impact and aims use [16], particularly use can affect human health. The guideline water quality standards and beverages is constantly monitored and updated so that is always in line with the current changes $[5,9]$. 
Theoretically shows that the vapor through stomata process produces more cleanness and pure water extraction without any treatment. It also confidentially gives the good potential for water drinkable for tested plants. This investigation may identify that the effects of soil, water content, toxic rubber and safe plants where drinkable water without any filtration.

Collector water from leave was analyzed based on drinking water standard through selected parameters such as $\mathrm{pH}, \mathrm{DO}$, turbidity, chloride, fluoride, nitrate, sulphate and magnesium. All testing was handled at water quality laboratory by $\mathrm{pH}$ and DO meters, thermometer, turbidity meter, Ion Chromatography (IC) machine and Atomic absorption spectrometer (AAS) machine. Groundwater and water leaves samples were analyzed and compared respectively.

In this study, the chemicals contained in the samples will collect one-day data sample (from 9.30 am to $5.30 \mathrm{pm}$ ) [17] to identify the quality of water of transpiration of seven (7) types of plant chosen from three (3) different regions. Samples was measured by using ion chromatography,atomic absorption spectrometer instrument and others apparatus such as temperature, turbidity, $\mathrm{DO}, \mathrm{pH}$, colour, magnesium, calcium, nitrate and chloride $[11,14,18]$. The comparison to classify water sample for each plants will analyze and standardize as a guideline manual.

\section{Results and Discussions}

\subsection{Water Quantity}

Plant leaf surface area affects the total volume of water that can be collected. The leaf that have a larger surface area such as banana leaf can produce more water transpiration in a time compared to small leaf surface area.

From preliminary studies have showed that all the trees transpiration rates by 8 hours period. A banana tree was higher collector of water samples, followed by flowers bells and rambutan trees (Table 1). Shrimp clip tree is the lowest. It showed that the rate of transpiration for a species depends on the characteristics of the plants it self other than environmental factors.

Table 1. Average transpiration rate collection

\begin{tabular}{|l|c|}
\hline Type of plant & $\begin{array}{c}\text { Average transpiration } \times \mathbf{~ ( 1 0}^{-\mathbf{6}} \mathbf{)} \\
(\mathbf{l} / \mathbf{s})\end{array}$ \\
\hline Banana & 5.5 \\
\hline Principal soursop & 3.4 \\
\hline Shrimp clip & 1.8 \\
\hline Flowerbeds setup & 3.3 \\
\hline Drasina & 3.1 \\
\hline Flowers bells & 4.1 \\
\hline Rambutan & 3.6 \\
\hline
\end{tabular}

\subsection{Water Quality}

According to preliminary study, the water extracted from all plants have good potential for drinking water and safe. It also showed that water quality was evaluated based on characteristics of plant for example; flower bells shows less secure features based on the content of the gummy that does not dissolve in the liquid. However, all the trees shows high 
turbidity values except drasina and soursop. This situation shows that the plant will produce a wide range of different water quality.

\section{Conclusions}

Through this transpiration method, maintain the number of flora that many on this earth for the well-being of all the object slighted up. In addition, the process of transpiration can continue to keep the air moist and helps atmosphere be able to reduce the temperature of the heat. In this study, the awareness study can be created about the importance of healthy drinking water quality and plant transpiration process itself. It is important not only to the water cycle on a rural and urban or global level it down acts as a solution to the survival in the forest looking for a source of water during emergencies. The existences of these plants have a very important role not only in the hydrological cycle but it can also serve as the urban landscape and give supply oxygen to peoples and living things. This feature is in keeping with the importance of this study in which the study are conduct as an alternative to the public drinking water if embattled clean water supply in the future.

Utmost appreciation and deepest gratitude to the UTHM hydro team of this study.

\section{References}

[1] O.V. De Sousa, G.D. Vechio Viera, J.D.J. De-Pinho, C.H. Yamamoto and M.S. Alves, Antinociceptive and anti-inflammatory activities of the ethanol extract of Annona muricata L. leaves in animal models. Int. J. of Molecular Sciences, 11(5), 2067-2078, (2010)

[2] N. W. Chan, Issues and challenges in water governance in Malaysia, Journal of environmental health science and engineering, 6(3), 143-148, (2009)

[3] E. Jequier, and F. Constant, Water as an essential nutrient: the physiological basis of hydration, J. of clinical nutrition, 64, 115-123, (2010)

[4] M. A. Fulazzaky, T. W. Seong, and M. I. Masirin, Assessment of Water Quality Status for the Selangor River in Malaysia. Water Air Soil Pollution, 205(1-4), 63-77, (2009)

[5] N. F. Gary, Drinking water quality. $2^{\text {nd }}$ ed. United States of America: Cambridge University Press, (2008)

[6] C. Chang, and J. Chang, Study on Simple Transpiration Model and Fitted Measurement Time for Dominant Plant at Mudstone Area in Taiwan, 12th ISCO Conference, Beijing, 244-250, (2002)

[7] H. Perlman, (2016) Retrieved on May 3, 2016 from http://water.usgs.gov/edu/watercycletranspiration.html

[8] T. Sterling, Transpiration-water movement through plants. Department of Entomology, Plant Pathology and weed science, (2004)

[9] F. R. Spellman, The drinking water handbook. $\mathbf{2}^{\text {nd }}$ ed. London: CRC press, (2012)

[10]C. Maria, Singureanu., H. Denisa, and B. Erszebet, Heliconias- novelties and applicability in floral art, J. of horticulture, forestry and Biotechnology, 18(1), 22-27, (2014)

[11]E. Steudle, How does water get through roots?, J. of Experimental Botany, 49(322), 775-788, (1998) 
[12]M. Rindam, T. N. Long Seman, R. Sulaiman, and R. Rashid, Proses sejatpeluhan tumbuhan terpilih sebagai kaedah mendapatkan dan menangani masalah sumber air, Malaysia, Malaysian J. of Society and Space, 6(2), 10 - 19, (2010)

[13] W. L. C. Muenscher, A Study of the Relation of Transpiration to the Size and Number of Stomata, American J. of Botany, 2(9), 487-504, (2016)

[14]W. M. Atwell, and N. B. Stout, Transpiration Rates under Controlled Environment : Species, Humidity, and Available Water as Variables, Ohio J. of Science. 62(1), 18-26, (1962)

[15]T. E. Dawson, S. S. Burgess, K. P. Tu, R. S. Oliveira, L. S. Santiago, J. B. Fisher, A. R. Ambrose, Nighttime transpiration in woody plants from contrasting ecosystems. Tree Physiology, 27(4), (2007)

[16]Food and Agriculture Organization of the United Nations (2014). Retrieved on June 20, 2016 from http://www.fao.org/world/regional/rap/index.asp

[17]A. E. Uduak, and S. U. Esther, Comparative phytochemical screening and nutritional potentials of the stems, leaves and flowers of allamanda cathartica (apocynaceae). Int. J. of science and technology, 4(6), 248-253, (2015)

[18]M. T. Bashir, S. Ali, A., Bashir, Health effects from exposure to sulphate and chlorides in drinking water. Pakistan J. of medical and health sciences, 6(3), 648 - 652, (2012). 